\title{
PENGEMBANGAN PROFIL OUTLET PADA PUSAT PERBELANJAAN MATARAM MALL
}

\author{
Lalu Arkan Zuhaedi ${ }^{1,}$ Dadang Priyanto, M.Kom ${ }^{2}$ \\ ${ }^{1)}$ Mahasiswa, ${ }^{2}$ Dosen Program Studi Teknik Informatika STMIK Bumigora Mataram \\ Jl. Ismail Marzuki Mataram, Telp (0370) - 634498 \\ 1alu.arkan@gmail.com, ${ }^{2}$ dadang.priyanto@ stmikbumigora.ac.id
}

\begin{abstract}
ABSTRAK
Ilmu pengetahuan dan teknologi informasi berkembang cukup pesat dan menghasilkan inovasi-inovasi baru yang senantiasa terus berubah ke arah yang lebih baik. Pada kenyataannya masih banyak pusat perbelanjaan atau toko yang membuat pembelinya kesusahan untuk mengetahui dan mencari produk yang diinginkan, karena bangunan pusat perbelanjaan yang begitu luas dengan banyak toko atau outlet yang berjejer didalamnya. Berdasarkan pemaparan diatas penulis akan mengembangkan sebuah aplikasi profil outlet pada pusat perbelanjaan berbasis multimedia. Agar informasi dari masing-masing toko atau outlet tersebut dapat di sampaikan dengan lebih interaktif, menarik, dan mempermudah pengunjung mencari barang yang di butuhkan. Metode pengembangan yang digunakan oleh penulis pada penelitian ini adalah metode versi Luther Sutopo yang memiliki enam tahap yaitu tahap Concept (Konsep), Design (Perancangan), Material Collecting (Pengumpulan Bahan), Assembly (Pembuatan), Testing (Ujicoba) dan Distribution (Distribusi). Hasil atau keluaran yang akan dicapai yaitu sebuah aplikasi profil outlet pada pusat perbelanjaan mataram mall berbasis multimedia yang melibatkan elemen-elemen multimedia seperti teks, gambar, suara, dan animasi yang dikemas dalam media penyimpanan DVD yang dapat dijalankan di media elektronik yaitu PC (Personal Computer). Kesimpulan yang diperoleh selama melakukan penelitian ini, penulis dapat menyimpulkan bahwa aplikasi yang dibangun sangat membantu pengunjung dalam proses pencarian informasi toko atau outlet dengan lebih mudah dan cepat.
\end{abstract}

Kata kunci : Profil Outlet, Pusat Perbelanjaan, Mataram Mall, Aplikasi Multimedia.

\begin{abstract}
ABSRACT
Science and information technology expand fast enough and yield new innovations which ever continue to change up at better. Practically still many shopping centre or shop making its buyer of adversity to know and look for wanted product, because shopping centre building which so wide of with many or shop of outlet which is many in it. Pursuant to presentation above writer will develop a profile application of outlet at shopping centre base on multimedia. So that to be information from each or shop of outlet the can in submitting with interest interaktif, interesting, and water down visitor look for goods which in requiring. Development method used by writer at this research is version method of Luther Sutopo owning six phase that is phase of Concept, Design, Material of Collecting, Assembly, Testing and of Distribution. Result or output to reach by that is a profile application of outlet at shopping centre of mataram mall base on multimedia entangling elements of multimedia like text, picture, voice, and tidy animation in storage media of DVD able to be run by in electronic media that is PC ( Personal Computer). Obtained Conclusion during conducting this research, writer can conclude that woke up application very is assisting of visitor in course of seeking of shop information or of outlet with interest easy to and quickly.
\end{abstract}

Keywords: Profile of Outlet, Shopping centre, Mataram Mall, Application of Multimedia.

pendidikan, pemerintah sampai dengan dengan kegiatan bisnis. Teknologi informasi akan

\section{PENDAHULUAN}

Ilmu pengetahuan dan teknologi informasi berkembang cukup pesat dan menghasilkan inovasi-inovasi baru yang senantiasa terus berubah ke arah yang lebih baik. Teknologi informasi telah memberikan peran yang sangat penting dalam kehidupan sehari-hari. Sudah saatnya kini masyarakat mulai memanfaakan teknologi informasi yang dapat mendukung berbagai macam kegiatan, mulai dari dunia memberikan nilai tambah dalam proses kegiatan

serta dapat memberikan kemudahan di berbagai macam bidang kegiatan, salah satunya dalam bidang multimedia komputer. Dalam hal ini elemen-elemen multimedia seperti Gambar, Video, Suara serta elemen lainya yang termasuk kedalam elemen pendukung, sudah banyak digunakan untuk membantu menjual suatu 
produk.

Seiring dengan perkembangan pembangunan di kota-kota besar metropolitan yang merupakan pusat bisnis, sudah tidak asing lagi jika terlihat gedung-gedeng berukuran raksasa. Bahkan sebagian besar adalah untuk keperluan kegiatan pusat perbelanjaan seperti Mall. Pusat perbelanjaan Mall yang didirikan oleh suatu organsasi baik pemerintah maupun swasta, tidak hanya di khususkan untuk kegiatan jual beli ataupun bisnis-bisnis lainnya, melainkan juga sebagai tempat hiburan, olahraga dan juga tempat untuk sekedar jalan-jalan.

Pada kenyataannya banyak pusat perbelanjaan atau toko yang membuat pembelinya kesusahan untuk mengetahui dan mencari produk yang diinginkan, karena bangunan dari pusat perbelanjaan yang begitu luas dengan banyak toko atau outlet yang berjejer didalamnya[2].

Berdasarkan hasil wawancara dari staf pegawai mataram mall, seringkali pengunjung mengalami kesulitan dalam mencari letak toko yang menyediakan produk barang dan jasa ataupun berbagai fasilitas yang mereka butuhkan karena ukuran gedung yang luas dan memiliki banyak tahap dan lantai, khususnya di Mataram mall yang dijadikan objek penelitian.

Berdasarkan pemaparan diatas penulis akan mengembangkan penelitian dari Lalu Ray Ramadh Sugara yaitu sebuah aplikasi profil outlet pada pusat perbelanjaan mataram mall berbasis multimedia, pada aplikasi sebelumnya yang dibangun hanya aplikasi outlet pada mataram mall 1 lantai I, II, III, dan IV. Untuk itu berdasarkan saran dari aplikasi yang sebelumnya, penulis akan mengembangkan aplikasi tersebut dengan menambahkan mataram mall II dan database pada setiap outlet agar informasi dari setiap outlet dapat diupdate dengan mudah. Agar informasi dari masingmasing toko atau outlet tersebut dapat di sampaikan dengan lebih interaktif, menarik, dan mempermudah pengunjung mencari barang yang di butuhkan.

\section{METODOLOGI}

\section{Metode Penelitian}

Seperti yang dijelaskan sebelumnya pada BAB I, metode yang digunakan penulis dalam penelitian ini adalah metode pengumpulan data yang terdiri dari pengamatan (Observasi), wawancara, studi literatur, kuesioner dan metode pengembangan multimedia versi Luther Sutopo yang terdiri dari 6 tahapan, yaitu concept, design, material collecting, assembly, testing dan distribution[3].

\section{Pengumpulan Data}

\section{A. Metode Pengumpulan Data}

Pengumpulan data dilakukan untuk memperoleh data-data yang dibutuhkan dalam pembuatan sebuah aplikasi. Metode pengumpulan data yang dilakukan adalah :

1. Observasi

Obervasi dilakukan secara langsung untuk memperoleh data-data yang dibutuhkan dalam membangun aplikasi profil setiap outlet pada mataram mall 1 dan 2. Data-data yang diperoleh dan informasi hasil pengamatan seperti:

- Jumlah toko yang terdapat di Mataram Mall 1

- Lantai 1 terdiri dari 21 toko

- Lantai 2 terdiri dari 13 toko

- Lantai 3 terdiri dari 13 toko

- Lantai 4 terdiri dari 11 toko

- Jumlah toko yang terdapat di Mataram Mall 2

- Lantai 1 terdiri dari 17 toko

- Lantai 2 terdiri dari 13 toko

- Lantai 3 teridiri dari 15 toko

- Foto-foto toko atau outlet pada mataram mall 1 dan 2

- Informasi jenis barang atau jasa yang disediakan oleh setiap toko atau outlet pada mataram mall 1 dan 2

- Denah Mataram Mall 1 dan Mataram Mall 2

- Informasi kontak toko atau outlet pada mataram mall 1 dan 2

2. Wawancara

Wawancara dillakukan kepada pegawai yang berada di tempat penelitian, tujuannya yaitu untuk mengetahui informasi yang jelas dan akurat. Wawancara merupakan komunikasi langsung antara peneliti dan responden. Untuk melakukan wawancara, baik peneliti maupun responden harus menggunakan bahasa dan pengertian yang sama, dapat menyampaikan dan menerima suatu pertanyaan atau dengan jelas

Dalam metode ini, penulis melakukan wawancara dengan staf pegawai mataram mall dari bagian marketing tentang media informasi apa saja yang digunakan toko- 
toko di mataram mall untuk mempromosikan barang atau jasa yang tersedia. Waktu pelaksanaan wawancara ini dilaksanakan pada tanggal 05 bulan juli tahun 2016 di Mataram Mall.

Kesimpulan dari hasil wawancara yang sudah dilakukan adalah sebagian besar toko tidak menggunakan media apapun untung mempromosikan barang yang dijual dikarenakan brand dari toko yang sudah terkenal, namun ada beberapa menggunakan brosur atau sepanduk yang di taruh di depan toko untuk memberikan informasi barang atau jasa yang tersedia.

3. Studi Literatur

Studi literatur merupakan kegiatan yang dilakukan untuk memperoleh datadata yang berkaitan dengan peta digital dalam membangun aplikasi profil outlet pada pusat perbelanjaan mataram mall 1 dan 2. Studi literatur yang Kuesioner

Metode ini dilakukan dengan cara membagikan kuisioner atau angket kepada pengunjung mataram mall dan mendemokan program aplikasi agar para pengunjung bisa menilai sejauh mana aplikasi Profil Outlet Pada Pusat Perbelanjaan Mataram Mall ini dapat bermanfaat bagi para pengunjung. Pada metode kuisioner ini penulis menggunakan 15 responden untuk menilai program aplikasi profil outlet ini.

\section{Metode pengembangan multimedia}

Metode pengembangan yang digunakan adalah metode pengmembangan multimedia versi Luther Sutopo yang terdiri daari 6 tahapan yaitu concept, design, material collecting, assembly, testing dan distribution[3].

\section{A. Concept}

Tahap concept (konsep) adalah tahap untuk menentukan tujuan dan siapa pengguna program (identifikasi audience), aplikasi (presentasi, atraktif dan lain-lain), tujuan aplikasi (hiburan, informasi dan lainlain). Pengonsepan bertujuan agar dalam pembuatan aplikasi Pengembangan Profil Outlet Pada Pusat Perbelanjaan Mataram Mall dapat terorganisasi dengan baik sehingga menghasilkan aplikasi yang baik pula.

Aplikasi Profil Outlet ini terdiri dari komponen - komponen multimedia seperti teks, animasi, gambar, suara yang dikemas sedemikian rupa sehingga aplikasi menjadi menarik dan mudah dimengerti oleh pengguna. Aplikasi Profil Outlet ini nantinya akan dibuat dengan menggunakan perangkat lunak Adobe Flash Profesional CS6.

Tabel 2.1 Tabel Konsep

\begin{tabular}{|c|c|c|}
\hline 1. & Judul & $\begin{array}{l}\text { Pengembangan Profil Outlet } \\
\text { Pada Pusat Perbelanjaan } \\
\text { Mataram Mall }\end{array}$ \\
\hline 2. & Audiens & Pengunjung Mataram Mall \\
\hline 3. & Tujuan & $\begin{array}{l}\text { Sebagai media informasi } \\
\text { bagi para pengunjung } \\
\text { mataram mall dalan mencari } \\
\text { lokasi toko dan fasilitas- } \\
\text { fasilitas yang tersedia di } \\
\text { mataram mall. }\end{array}$ \\
\hline 4 & $\begin{array}{l}\text { Pengumpulan } \\
\text { Data }\end{array}$ & $\begin{array}{l}\text { Dalam pengumpulan data } \\
\text { dilakukan dengan cara } \\
\text { observasi langsung di } \\
\text { tempat penelitian, } \\
\text { mewawancarai staf pegawai } \\
\text { mataram mall dan studi } \\
\text { literatur yaitu dengan cara } \\
\text { membaca buku, artikel, } \\
\text { jurnal dan refrensi-refrensi } \\
\text { lain yang terkait. }\end{array}$ \\
\hline 5 & Gambar & $\begin{array}{l}\text { Gambar diperoleh dari } \\
\text { observasi langsung di } \\
\text { tempat penelitian dengan } \\
\text { menggunakan kamera. }\end{array}$ \\
\hline 6 & Audio & $\begin{array}{l}\text { Musik instrument yang } \\
\text { download dari internet. }\end{array}$ \\
\hline 7 & Logo Toko & $\begin{array}{l}\text { Logo toko diperoleh dari } \\
\text { observasi di tempat tujuan } \\
\text { dengan cara mengambil } \\
\text { gambar dengan kamera, dan } \\
\text { untuk pembuatannya } \\
\text { menggunakan Corel Draw } \\
\text { X4 dengan cara menjiplak } \\
\text { logo toko yang sudah di } \\
\text { ambil menggunakan kamera. }\end{array}$ \\
\hline
\end{tabular}

\subsection{A.1 Tujuan aplikasi}

Dari tahap ini penulis telah menentukan bahwa program aplikasi ini tujuannya adalah sebagai media informasi untuk membantu dan memudahkan pengunjung mataram mall dalam mencari lokasi toko dan fasilitas-fasilitas lain yang ingin dikunjungi dengan penyampaian informasi yang lebih menarik karena informasi yang di tampilkan berupa text, gambar, suara dan animasi.

\subsection{A.2 Sasaran pengguna aplikasi}


Sasaran dari pembuatan aplikasi ini adalah untuk masyarakat umum, khususnya pengunjung mataram mall.

\subsection{A.3 Konten informasi}

Aplikasi ini terdiri dari 3 (Tiga) kelompok informasi yaitu:

1. Informasi Toko, berisi tentang informasi umum barang dan jasa yang di sediakan didalamnya

2. Galery, berisi tentang foto-foto bagian depan toko atau barang dan jasa yang di jual di dalam toko tersebut

3. Contact, berisi tentang kontak yang bisa dihubungi di dalam toko tersebut seperti : No telephone, e-mail, twitter, facebook, Website dll.

Tabel 2.2 Keterangan informasi

\begin{tabular}{|c|l|l|}
\hline No & Kelompok informasi & \multicolumn{1}{|c|}{ Cara penyampaian } \\
\hline 1 & Informasi Toko & Text \\
& & \\
\hline 2 & Gallery & Teks dan gambar \\
\hline 3 & Kontak & Teks dan gambar \\
\hline
\end{tabular}

\section{B. Desain (Design)}

\subsection{B.1 Desain Sistem Database}

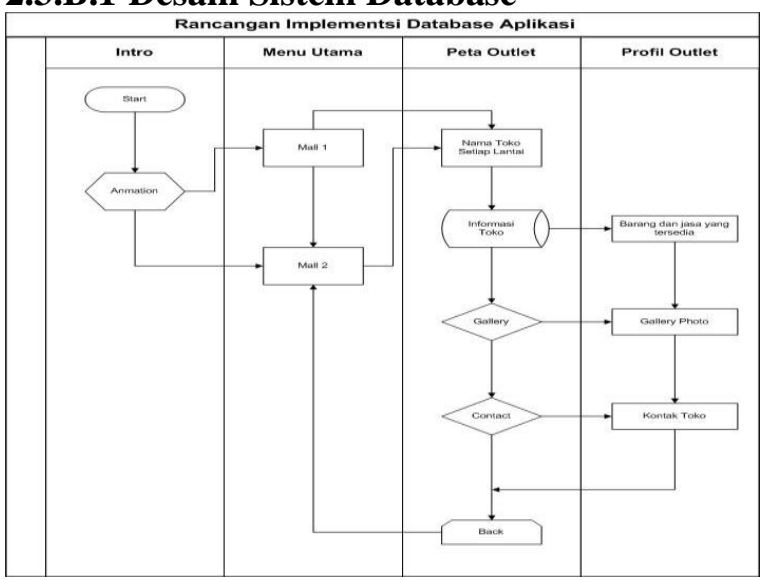

Gambar 2.1 Desain Sistem Database

\subsection{B.2 Struktur Database}

Struktur data dapat disesuaikan menurut kebutuhan, sesuai dengan aplikasi yang akan dibuat. Aplikasi yang dibuat ini terdiri dari 1 file database, dan didalam file database ini terdapat table, yang dimana banyak table disesuaikan dengan banyak outlet yang ada di mataram mall.

1. Struktur tabel

Struktur tabel pada aplikasi atau program terlihat pada tabel 3.2.

Tabel 2.3 Struktur tabel

\begin{tabular}{|c|c|c|c|c|}
\hline $\begin{array}{l}\mathrm{N} \\
\mathrm{O}\end{array}$ & $\begin{array}{l}\text { Nama } \\
\text { Field }\end{array}$ & Ty & Size & $\begin{array}{l}\text { Descri } \\
\text { ption }\end{array}$ \\
\hline
\end{tabular}

\begin{tabular}{|l|l|l|l|l|l|}
\hline 1 & No & Integer & 11 & $\begin{array}{l}\text { Primary } \\
\text { key }\end{array}$ & $\begin{array}{l}\text { Auto__ } \\
\text { Incre } \\
\text { ment }\end{array}$ \\
\hline 2 & Tersedia & Varchar & 53 & & \\
\hline
\end{tabular}

\subsection{B.3 Desain Navigasi/Struktur Aplikasi}

Dalam perancangan aplikasi Multimedia yang akan dibangun, dimulai dari Intro sebagai opening, kemudian masuk ke dalam menu utama.

Pada menu utama terdapat enam sub menu, yaitu menu Lantai 1, Lantai 2, Lantai 3, Lantai 4, Help dan About. Pada menu Lantai 1, Lantai 2, Lantai 3 dan Lantai 4 terdapat sub menu, yaitu menu nama outlet yang terdapat di masing-masing lantai pada mataram Mall 1 dan 2. Kemudian pada menu masing masing outlet terdapat tiga sub menu, yaitu informasi barang yang tersedia, galery dan kontak.

\subsection{B.4 Sistem Navigasi}

Struktur navigasi yang di gunakan adalah model hierarki dengan modifikasi sepenuhnya. Tambahan pada perancangan model dapat dilihat pada penggunaan scene 1 (intro, menu utama atau home) yang dihubungkan dengan scene 2 (lantai1). Kemudian scene 2 (lantai1) mempunyai hubungan dengan scene 3 (lantai2), scene 4 (lantai3) dan scene 5 (lantai4) mall 1. Kemudian pada setiap lantai, yaitu lantai1, lantai2 dan lantai3 mall 1 terdapat button atau tombol yang berbentuk anak panah, yang dimana tombol tersebut berfungsi untuk menuju ke lantai yang sama pada mall 2. Gambar 3.1 memperlihatkan struktur navigasi selengkapnya. Hasil dari perancangan struktur navigasi berupa diagram hierarki yang menggambarkan hubungan antar scene.

Berikut adalah desain navigasinya : 


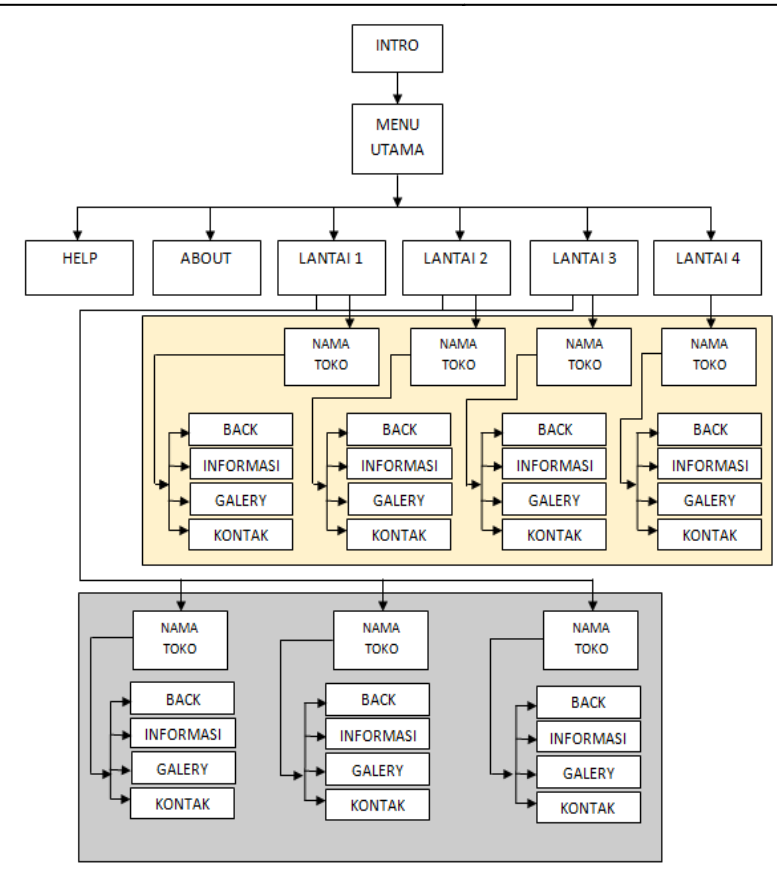

Gambar 2.2 Struktur navigasi model Hirarki 2.3.B.5 Desain Layout Aplikasi

Layout aplikasi adalah suatu tahapan awal dari rancangan tampilan multimedia interaktif. Desain layout dari aplikasi yang akan dikembangkan ini adalah berdasarkan dari desain layout pada aplikasi yang pertama. Sebelum dibentuknya tampilan yang akan digunakan dalam aplikasi tersebut. Terdapat beberapa layout aplikasi yaitu :

1. Layout informasi toko

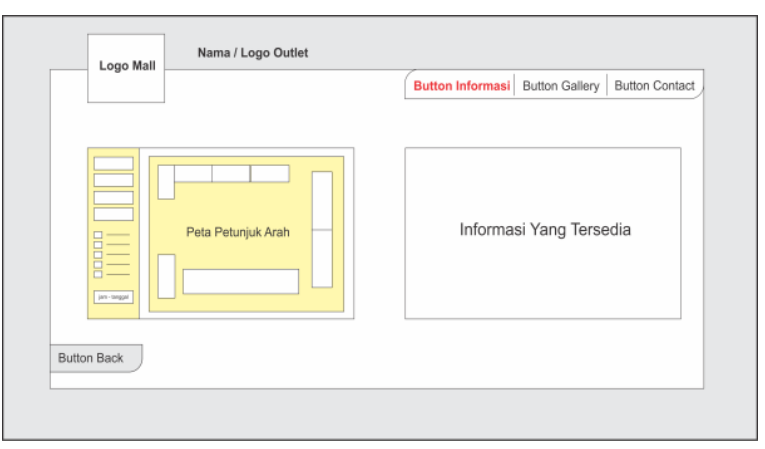

Gambar 2.3 Layout informasi toko

Pada layout menu informasi toko

1) Button informasi toko menuju penjelasan barang-barang yang tersedia di dalam toko.

2) Button Galery menuju ke Galery.

3) Button Contact menuju ke Contact.

4) Button Back yaitu kembali ke denah lokasi toko.

\section{Layout Galery}

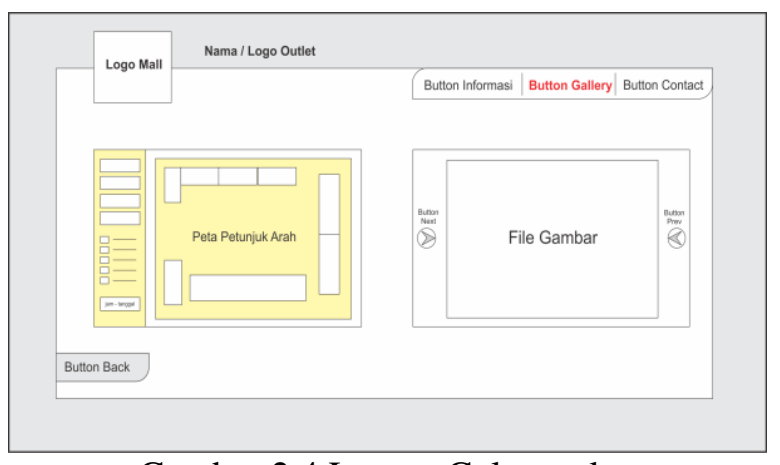

Gambar 2.4 Layout Galery toko

Pada layout menu Galery

1) Button galery menuju foto foto barang yang tersedia di dalam toko.

2) Button Next menuju ke foto-foto yang berikutnya.

3) Button Prev yaitu kembali ke foto yang sebelumnnya

4) Button Informasi menuju ke barang-barang tersedia.

5) Button Kontak menuju ke Contact.

6) Button Back yaitu kembali menuju ke denah lokasi toko.

\section{Layout Contact}

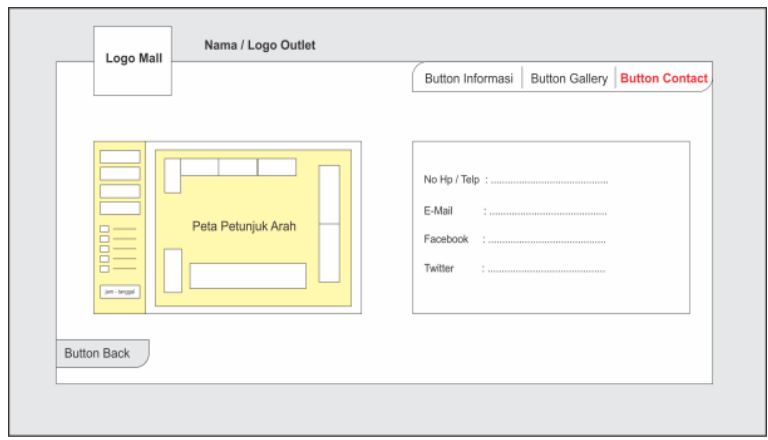

Gambar 2.5 Layout menu kontak

Pada layout menu kontak

1) Button Kontak berisi tentang kontak yang bisa dihubugi.

2) Button Informasi menuju ke Barang Tersedia.

3) Button Galery menuju ke Galery.

4) Button Back yaitu kembali ke denah lokasi toko.

\subsection{B.6 Storyboard}

Tabel 2.4 Storyboard aplikasi

\begin{tabular}{|l|l|l|l|}
\hline $\mathbf{N}$ & INTERFACE & LINK & AUDIO \\
\hline o. & INTE & \\
\hline
\end{tabular}




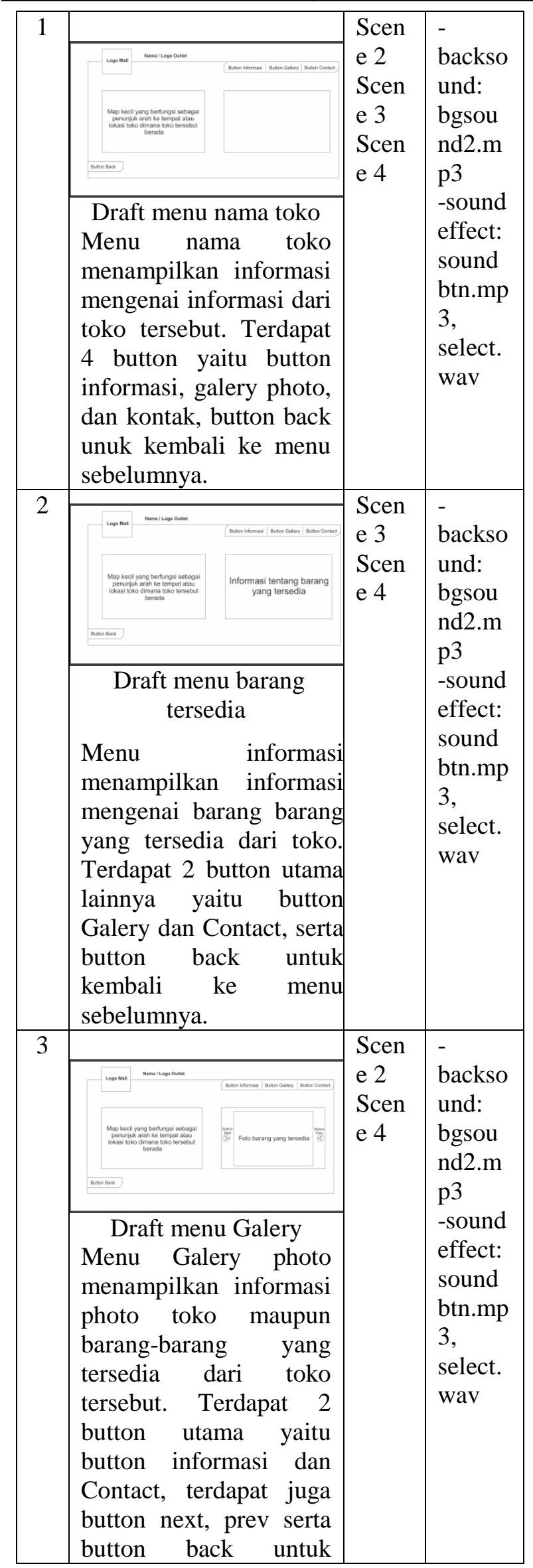

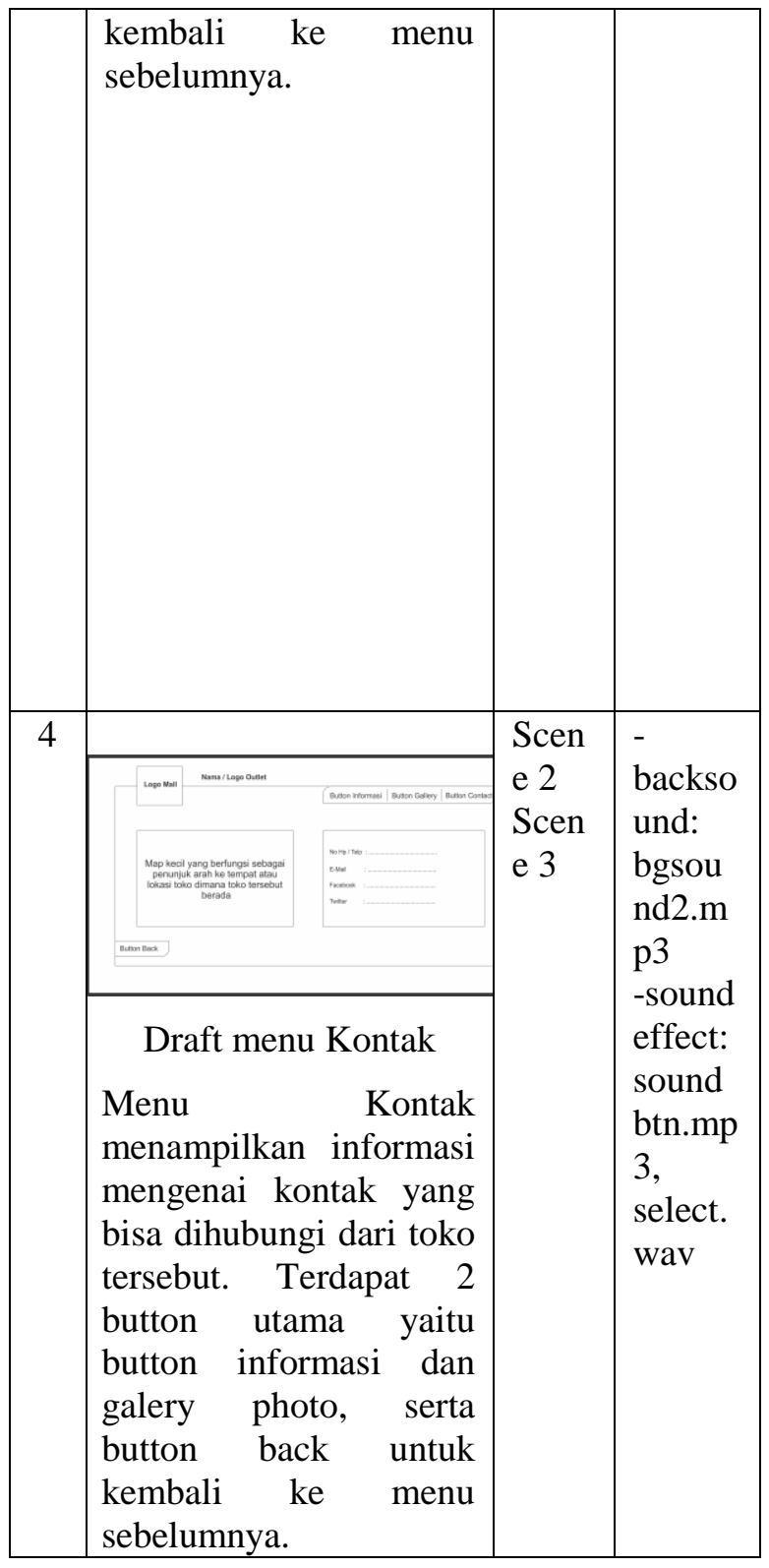

\section{Material collecting}

Material collecting adalah tahap pengumpulan bahan. Bahan yang dikumpulkan adalah image atau gambar, audio, bacground, dan image-image pendukung lain. Pada tahap ini biasa dilakukan secara paralel dengan tahap assembly. Sebagian besar image diambil degan di foto secara langsung kemudian di edit seperlunya menggunakan perangkat lunak Adobe Photoshop. Setelah tahap pengumpulan bahan selesai dilakukan perancangan akan dilakukan ke tahap selanjutnya, yaitu assembly.

\subsection{C.1 Kebutuhan sistem}

Dalam membangun sebuah sistem terdapat dua jenis kebutuhan yaitu: 
1. Kebutuhan fungsional

Kebutuhan fungsional yaitu kebutuhan yang berisi proses-proses apa saja yang bisa dilakukan oleh sistem atau program.

- Sistem ini mampu memberikan informasi barang atau jasa secara umum yang tersedia pada setiap toko atau outlet pada mataram mall 1 dan 2 .

- Sistem ini menyediakan foto-foto dari setiap toko atau outlet.

- Sistem ini menyediakan informasi kontak dari setiap toko atau outlet.

2. Kebutuhan non fungsional

Kebutuhan yang lebih menitik beratkan pada properti prilaku yang dimiliki sistem.

a. Operational

- PC minimal pentium 3

- Memory $1 \mathrm{~Gb}$

- Hardisk $320 \mathrm{~Gb}$

- Keyboard

- Speaker

- Mouse

- Cd-ROM

b. Keamanan

Sistem ini tidak dilengkapi tombol exit untuk menghindari supaya program tidak di close selama masih dibutuhkan. c.Informasi

Sistem ini juga menyediakan informasi mengenai tata cara dalam menggunakan apalikasi atau program.

\section{Assembly}

Pada tahap pembuatan ini akan dilakukan penggabungan semua material kedalam proyek berdasarkan pada tahap design, seperti storyboard dan struktur navigasi.

\section{E. Testing}

Testing (pengujian) merupakan tahap dilakukan setelah menyelesaikan tahap pembuatan (Assembly) dengan cara menjalankan sebuah aplikasi/program yang telah dibuat dan melihatnya apakah ada kesalahan atau tidak. Testing terlebih dahulu dilakukan dilingkungan pembuat sendiri dimana pengujian dilakukan. Apabila nantinya terjadi ketidak cocokan terhadap desain dan terdapat kesalahan maka akan dilakukan perbaikan pada aplikasi sehingga sesuai dengan desain yang telah dirancang. Tahap ini disebut juga sebagai tahap pengujian alpha (alpha test) dimana pengujian dilakukan oleh pembuat terlebih dahulu atau lingkungan pembuatnya sendiri. Setelah pengujian dilakukan oleh pembuat dan sudah tidak ditemukannya error pada aplikasi kemudian melakukan pengujian kepada pengguna (beta test) dengan cara memperlihatkan aplikasi yang dibuat dan memberikan sebuah kuisioner agar pengguna dapat menilai apakah aplikasi tersebut menarik atau tidak. Adapun kuisioner yang akan di berikan pembuat untuk pengguna :

Tabel 2.5 Tabel kuesioner ujicoba aplikasi untuk pengunjung

\begin{tabular}{|c|l|l|l|l|l|}
\hline \multirow{2}{*}{ No } & \multicolumn{2}{|c|}{ Pertanyaan } & \multicolumn{3}{|c|}{ Penilaian } \\
\cline { 2 - 5 } & \multicolumn{1}{|c|}{ SS } & S & KS & STS \\
\hline 1 & $\begin{array}{l}\text { Program mudah } \\
\text { digunakan }\end{array}$ & & & \\
\hline 2 & $\begin{array}{l}\text { Tampilan menu, } \\
\text { button, dan animasi } \\
\text { didalam aplikasi } \\
\text { menarik }\end{array}$ & & & \\
\hline 3 & $\begin{array}{l}\text { Tex yang terdapat } \\
\text { didalam aplikasi baik } \\
\text { text pada button } \\
\text { maupun text lainnya } \\
\text { terlihat jelas }\end{array}$ & & & & \\
\hline 4 & $\begin{array}{l}\text { Gambar yang } \\
\text { terdapat pada sub } \\
\text { menu galery photo } \\
\text { jelas dan menarik }\end{array}$ & & & & \\
\hline 5 & $\begin{array}{l}\text { Tombol yang } \\
\text { digunakan didalam } \\
\text { aplikasi sudah sesuai } \\
\text { dengan fungsinya }\end{array}$ & & & & \\
\hline 6 & $\begin{array}{l}\text { Sound yang terdapat } \\
\text { pada button dan } \\
\text { backsound aplikasi } \\
\text { jelas dan menarik }\end{array}$ & & & & \\
\hline
\end{tabular}

Keterangan table :

SS : Sangat Setuju S : Setuju

KS : Kurang Setuju STS : Tidak Setuju

\section{F. Distribution}

Pendistribusian yang akan dilakukan tergantung pada kapasitas program yang telah jadi, bisa memakai media floppy disk atau juga CD. Pada kasus ini, setelah program jadi dalam bentuk .exe., program atau aplikasi disimpan dalam CD dengan memakai perangkat lunak Nero yang 
nantinya program bisa langsung dijalankan melalui $\mathrm{CD}$.

\section{HASIL DAN PEMBAHASAN \\ A. Hasil}

A. Halaman intro

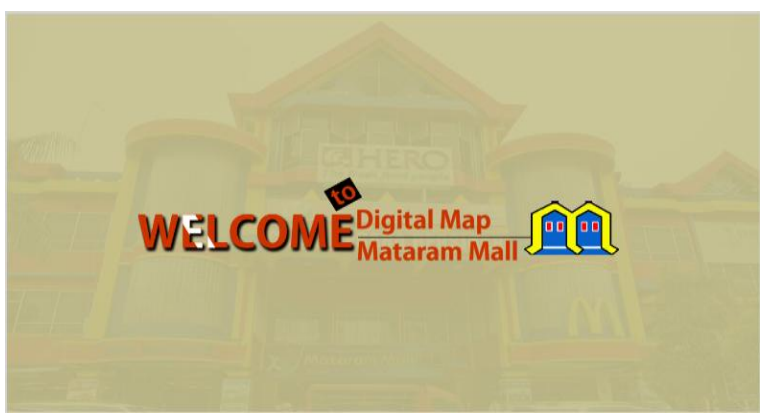

Gambar 3.1 Halaman menu intro

Halaman di atas adalah tampilan menu intro sambutan ketika program pertama kali di jalankan dimana setelah intro berakhir kemudian akan muncul halaman menu utama dari peta digital mataram mall.

\section{B. Halaman menu utama}

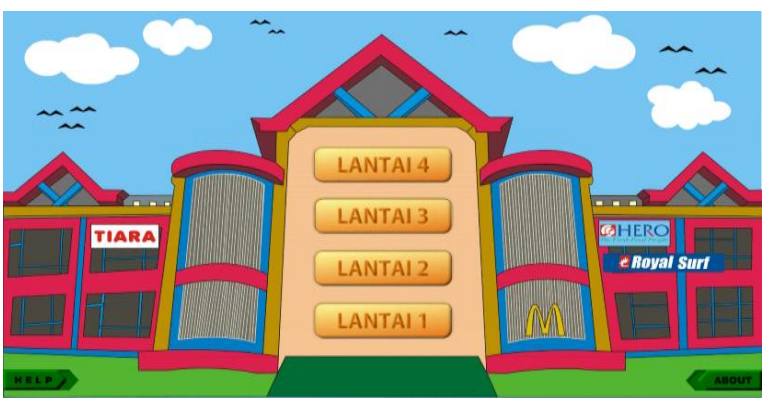

Gambar 3.2 Menu utama

Gambar di atas adalah tampilan halaman menu utama, dimana terdapat 6 buah tombol atau button dimana 4 di antaranya adalah tombol untuk menuju lantai 1, lantai 2, lantai 3, lantai 4 dan 2 tombol masing-masing berfungsi untuk menuju ke halaman help dan halaman about dari program atau aplikasi.

C. Halaman help

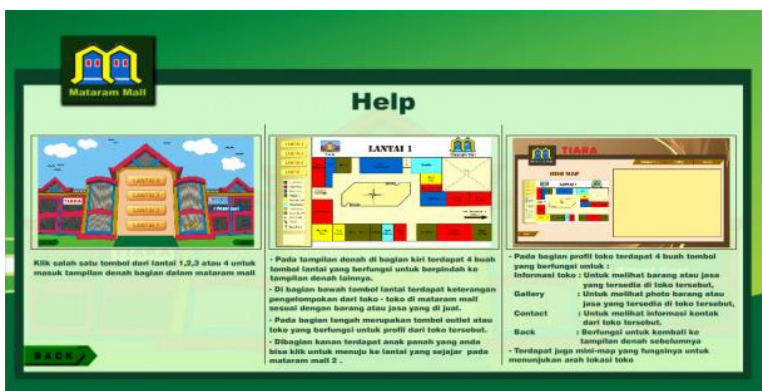

Gambar 3.3 Halaman menu help

Halaman menu help terdiri dari deskripsi teks mengenai tata cara atau panduan penggunaan program aplikasi peta digital mataram mall dimana di dalamnya terdapat button back yang berfungsi untuk kembali ke menu utama.

D. Halaman about

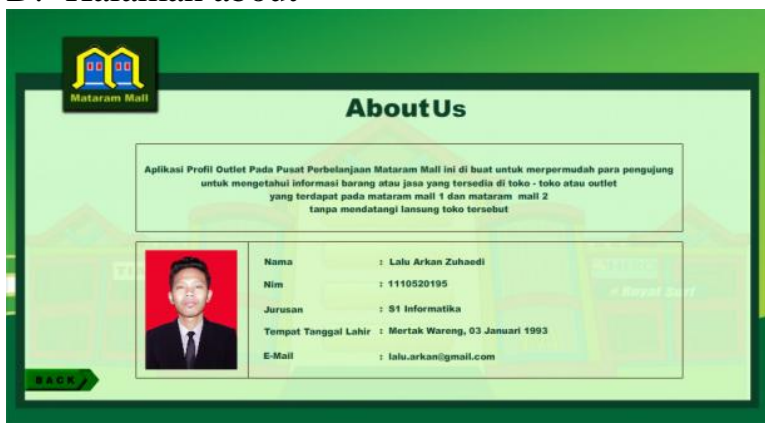

Gambar 3.4 Halaman menu about

Halaman menu about berisi tentang informasi mengenai program

E. Halaman sub menu informasi toko pada tiara lantai 1

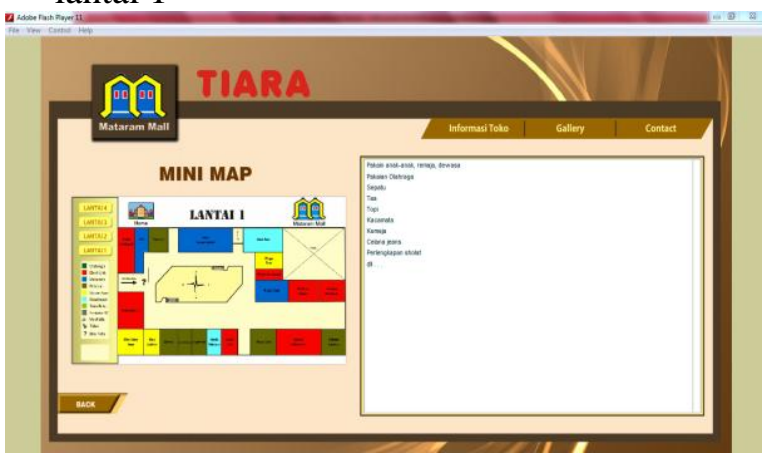

Gambar 3.5 Halaman menu informasi toko pada tiara

Halaman ini akan muncul saat pengunjung memilih button Tiara pada halaman menu utama lantai 1, disini akan di deskripsikan mengenai barang-barang yang dijual atau yang tersedia di toko tiara mataram mall. Selain itu disediakan juga map kecil yang berfungsi sebagai penunjuk arah dari map dimana pengunjung berada pada saat itu menuju lokasi toko yang ingin 
dikunjungi.

F. Halaman menu gallery pada tiara lantai 1

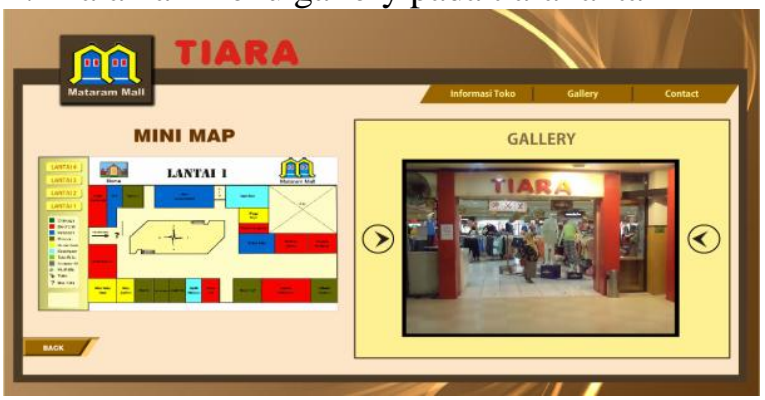

Gambar 3.6 Halaman menu galery photo tiara mataram mall

Halaman ini akan muncul saat pengunjung memilih button Gallery pada button sub menu tiara, disini akan di tampilkan beberapa foto atau gambar barang-barang yang dijual di toko tiara, dan untuk gambar selanjutnya pengunjung dapat memilih button next, untuk kembali pada gambar sebelumnnya pengunjung dapat memilih button preview.

G. Halaman menu kontak pada tiara lantai 1

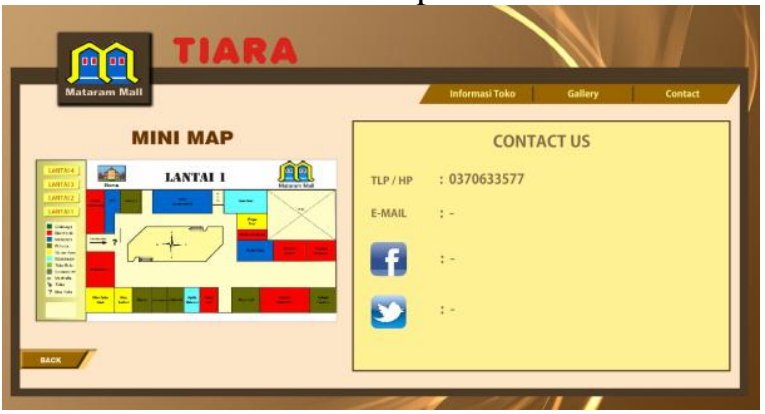

Gambar 3.7 Halaman menu kontak pada tiara mataram mall

Pada halaman ini akan di paparkan mengenai kontak yang bisa di hubungi dari toko tiara mataram mall.

\section{Pembahasan \\ B. Evaluasi}

Evaluasi dilakukan untuk mengetahui apakah program yang sudah dibangun, dapat bermanfaat dan diterima oleh pengguna. Pengujian pertama dilakukan oleh penulis dan selanjutnya dilakukan oleh beta test atau pengguna akhir dengan cara mengisi angket yang akan diberikan kepada pengunjung yang telah mencoba pencarian toko atau barang dengan menggunakan peta digital.

\section{Alpha Test}

Alpha testing dilakukan langsung oleh pembuat program untuk menguji apakah program yang telah dbuat berjalan dengan benar.

\section{Beta Test}

Beta testing dilakukan dengan metode angket dimana jumlah sampel pengguna pada aplikasi pengembangan profil outlet pada pusat perbelanjaan mataram mall diambil secara acak dengan jumlah responden 15 orang, dengan cara memberikan pengguna menggunakan aplikasi dan memberi kuisioner kepada pengguna yang telah selesai mencoba untuk di isi. Berdasarkan data hasil kuisioner, dapat dicari persentase dari masing-masing jawaban dengan menggunakan rumusan sebagai berikut :

$$
\mathrm{Y}=\sum \mathrm{jr} / \mathrm{q} * 100
$$

Keterangan :

$\mathrm{Y}=$ Nilai Persentase

$\sum j \mathrm{r}=$ Total Seluruh Jawaban Responden

$\mathrm{q}=$ Jumlah Responden

\section{SIMPULAN DAN SARAN}

\section{Kesimpulan}

Berdasarkan hasil dari pembahasan serta hasil uji coba program pada penelitian ini, dapat ditarik suatu kesimpulan bahwa :

1. Aplikasi Profil Outlet Pada Pusat Perbelanjaan Mataram Mall Berbasis Multmedia menggunakan Adobe Flash Professional CS6 yang dapat digunakan untuk memudahkan penyampaian informasi kepada pengunjung Mataram Mall mengenai lokasi toko atau fasilitasfasilitas yang ada di Mataram Mall, informasi yang ditampilkan lebih menarik karna menampilkan unsur-unsur multimedia seperti teks, gambar, suara dan animasi.

2. Informasi yang ditampilkan program yang dikembangkan penulis sesuai dengan informasi asli dari masing-masing outlet yang terdapat di Mataram Mall itu sendiri.

3. Aplikasi profil outlet ini dapat mempermudah pihak Mataram Mall dalam menyampaikan informasi mengenai outlet yang terdapat di Mataram Mall.

4. Berdasarkan hasil pengisian angket atau kuesioner oleh para pengunjung Mataram Mall, program yang dibuat penulis ini mudah dijalankan, konten - konten informasi mengenai profil outlet yang ditampilkan jelas dan menarik sehingga mempermudah pengunjung dalam mendapatkan informasi dari setiap outlet dari pusat perbelanjaan Mataram Mall. 


\section{Saran}

Melihat hasil akhir program dan hasil yang diperoleh pada saat pengujian, penulis merasa aplikasi yang dihasilkan masih belum sempurna. Untuk menyempurnakan program pada pengembangan selanjutnya, penulis dapat memberikan beberapa saran, yaitu sebagai berikut:

1. Memperbanyak fitur pada aplikasi profil outlet.

2. Menambahkan lebih banyak animasi pada elemen - elemen pembangun program sebagai efek.

3. Untuk ke depannya diharapkan, tampilan dari profil outlet ini menggunakan tampilan 3 dimensi agar tampilannya terlihat lebih menarik.

Demikian kesimpulan dan saran dari penulisan penelitian ini, dan dengan harapan dapat bermanfaat bagi semua pihak, saran yang bersifat membangun sangat diharapkan untuk dapat menyempurnakan penelitian ini.

\section{UCAPAN TERIMA KASIH}

1. Ibu Komariyuli Anwariyah, ST.,M.Kom., selaku Ketua STMIK Bumigora Mataram.

2. Ibu Ni Gusti Ayu Dasriani, M.Kom., selaku Ketua Program Studi S1 Teknik Informatika STMIK Bumigora Mataram

3. Bapak Dadang Priyanto, M.Kom., selaku Dosen pembimbing yang telah meluangkan waktunya dan memberikan masukanmasukan dalam membimbing penulis.

4. Bapak Lalu Iman Setiawan selaku HRD yang telah memberikan informasi dalam menyelesaikan penelitian pada Mataram Mall.

5. Bapak dan Ibu Dosen yang telah memberikan ilmu pengetahuan selama penulis duduk dibangku kuliah.

6. Bapak dan Ibu tersayang yang telah memberikan dukungan sebesar-besarnya, dan selalu setiap saat mendo'akan dimanapun penulis berada.

7. Teman-teman dan sahabat yang selalu memberikan bantuan dan dukungan dalam menyelesaikan penelitian ini.

\section{REFRENSI}

[1] Binanto, Iwan. 2010. "Multimedia DigitalDasar Teori dan Pengembangannya", Yogyakarta : Andi Offset.

[2] Sugara, L. Ray Ramadh. (2014). Profil
Outlet Pada Pusat Perbelanjaan Mataram Mall.

[3] Sutopo, Ariesto Hadi. (2003). Multimedia Interaktif dengan Flash. Graha Ilmu. Yogyakarta.

[4] Suyanto, M. 2005, Multimedia Alat Untuk Meningkatkan Keunggulan Bersaing. Yogyakarta : Andi Offset 